$? \quad$ LA-UR $-82-1830$

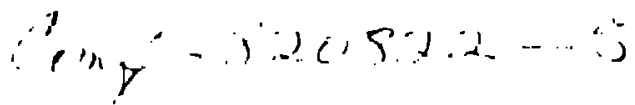

\title{
MASTER
}

$42-118:-822-1830$

$0[0 ; 2019579$

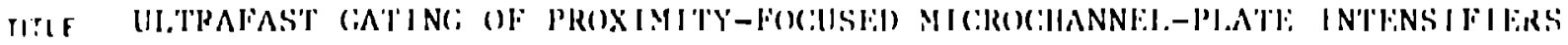

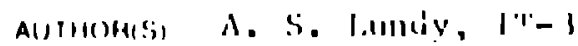

A. H. I verisun, l:-

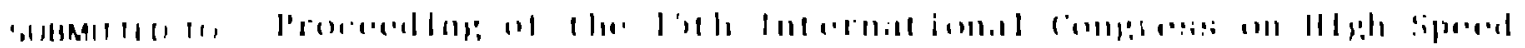

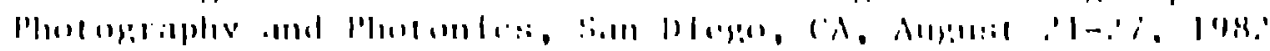

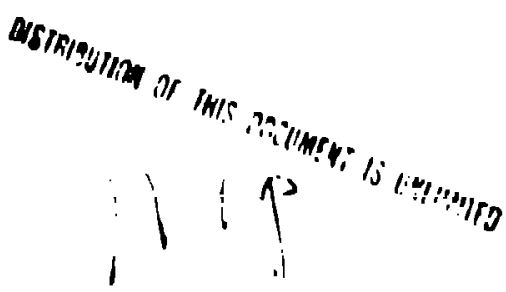

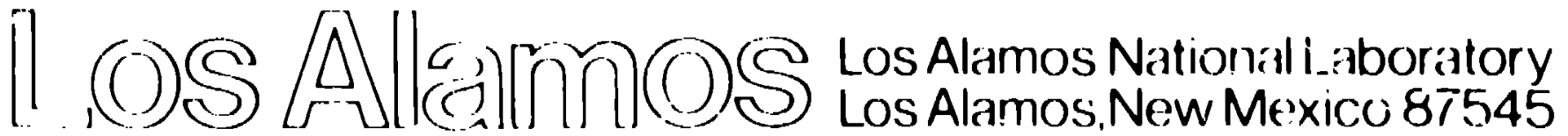




\author{
Ultrafast gating of proximity-focused microchannol-plate intensifuers \\ hrvid S. Lundy, International Technology off ice \\ A. Evan Iversun, Electronics Division \\ Los Alamos Naclonal Lavoratory \\ Unlversity of California, Los Mlamus, New Mexicu 87s4d
}

\begin{abstract}
Abstroct

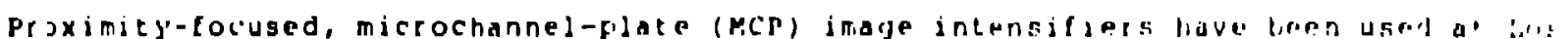

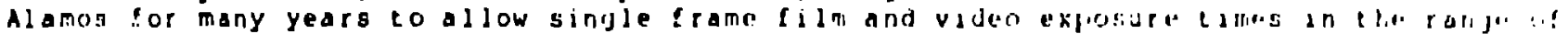

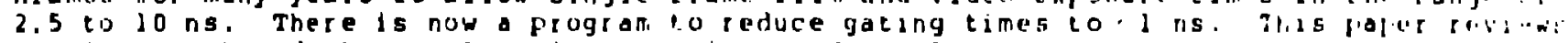
previuus work and the problems in acheving good resolution wilh galing tir.a uf. lis.

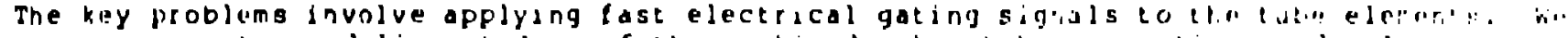

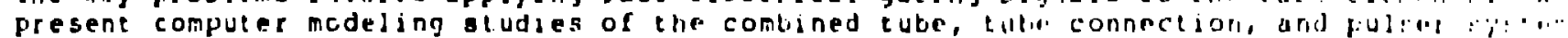

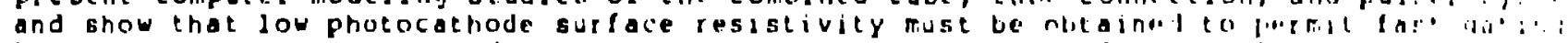

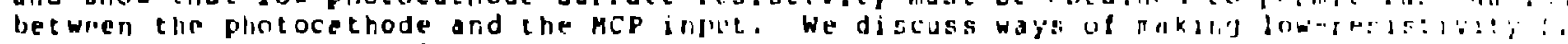

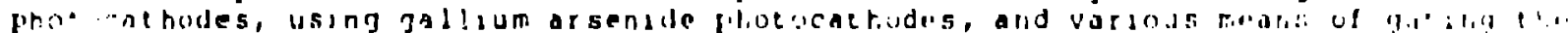

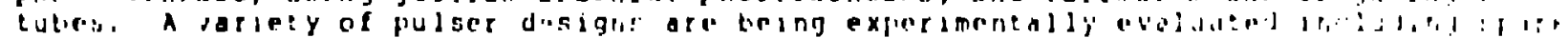

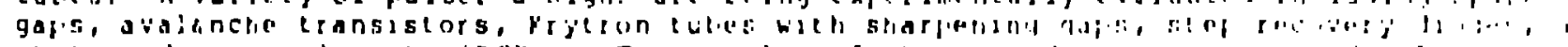

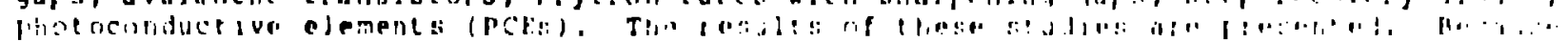

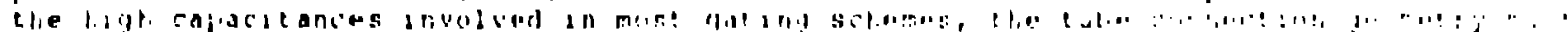

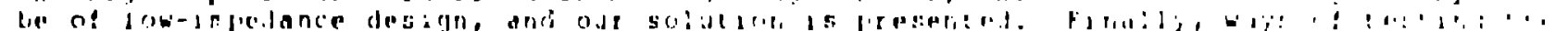

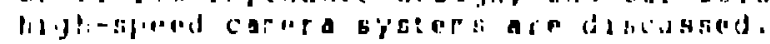

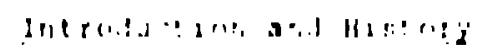

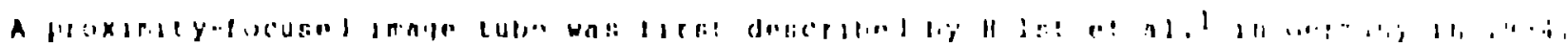

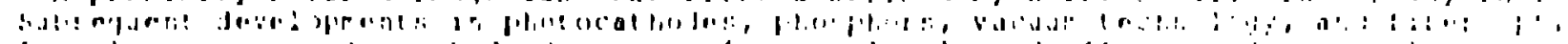

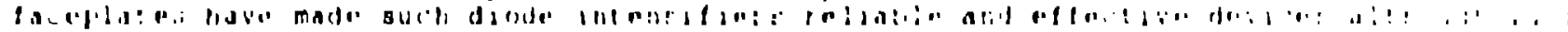

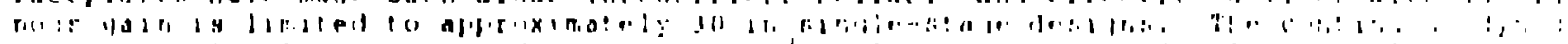

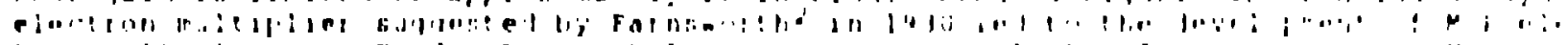

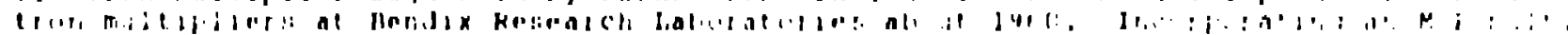

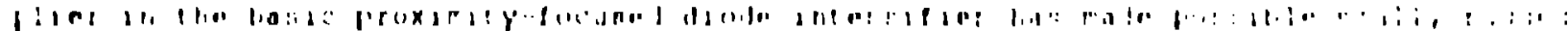

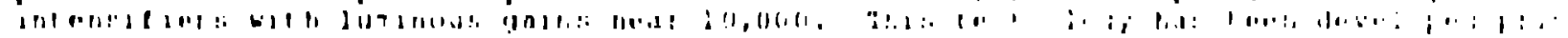

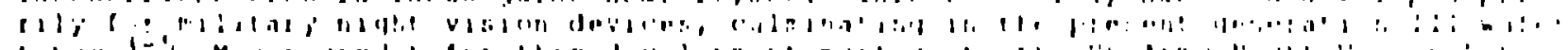

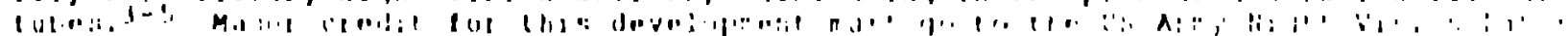

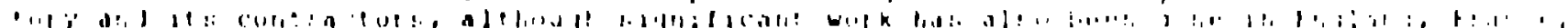

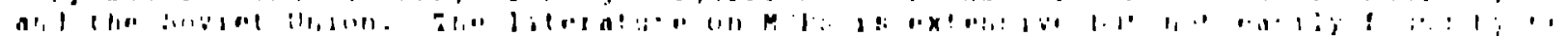

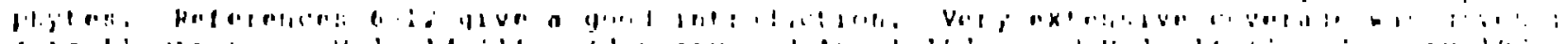
A., I:a, 1, 1,

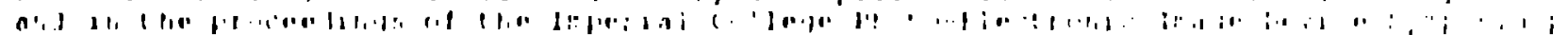

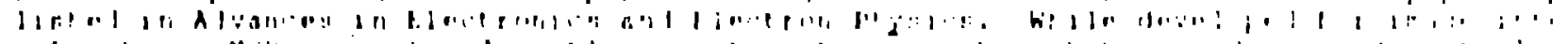

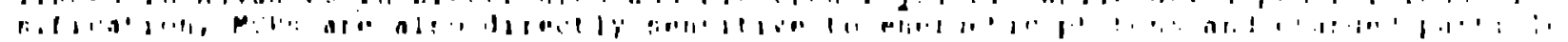

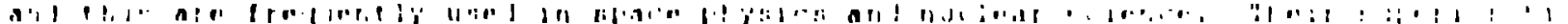

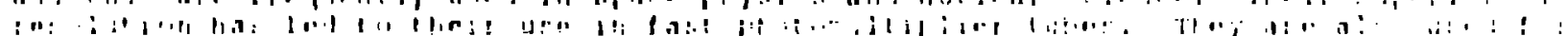

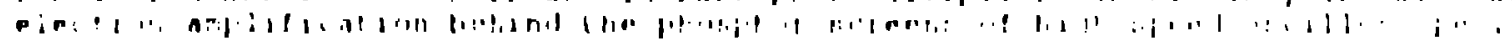

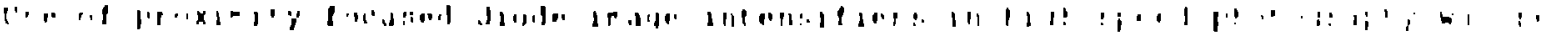

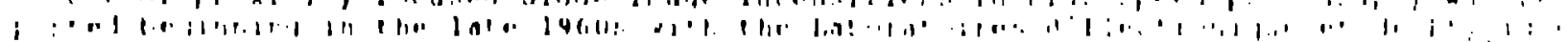

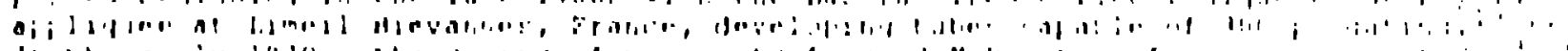

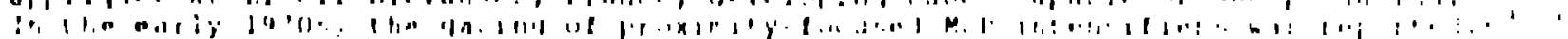

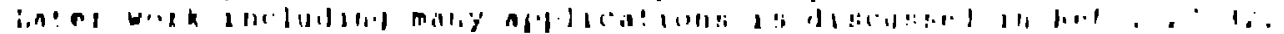

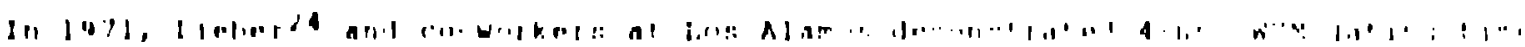

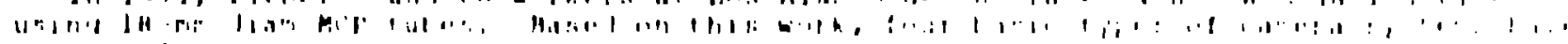

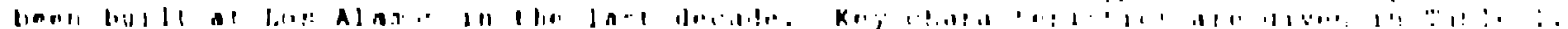




\begin{tabular}{|c|c|c|c|c|}
\hline $\begin{array}{c}\text { Tube } \\
\text { Diameter }\end{array}$ & $\begin{array}{l}\text { Shortest } \\
\text { Practical } \\
\text { Gating time }\end{array}$ & $\begin{array}{l}\text { Output } \\
\text { Medid }\end{array}$ & $\begin{array}{l}\text { Principal } \\
\text { Developers }\end{array}$ & Relerences \\
\hline $\begin{array}{l}18 \mathrm{~mm} \\
25 \mathrm{~mm} \\
25 \mathrm{~mm}\end{array}$ & $\begin{array}{l}2.5 \mathrm{~ns} \\
10 \text { to } 20 \mathrm{~ns} \\
5 \text { to } 10 \mathrm{~ns}\end{array}$ & $\begin{array}{l}\text { vidicon tube } \\
\text { vidicon tube } \\
25 \mathrm{~mm} \text { (Electric } \\
\text { lijm advance) }\end{array}$ & $\begin{array}{ll}\text { Group } & P-15 \\
\text { Group } & P-15 \\
\text { Group } & P-14\end{array}$ & $\begin{array}{l}33 \\
-- \\
--\end{array}$ \\
\hline $40 \mathrm{~mm}$ & $\begin{array}{l}10 \text { to } 15 \text { ng } \\
\text { loff:rs multi } \\
\text { puljing capa- } \\
\text { bility }\end{array}$ & $(4=\mathrm{mm} \cdot 5 \cdot(\mathrm{i}) \mathrm{m})$ & 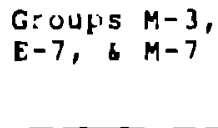 & $\begin{array}{c}34 \\
(p a d s e r \\
\text { olidj') }\end{array}$ \\
\hline
\end{tabular}

Over 75 cameras have been bujle at Los Alamos, and several of the 40-nm car. is hire

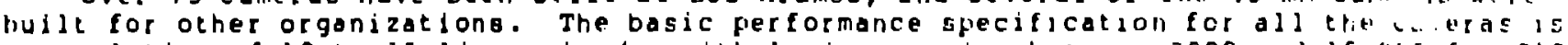
a Tesolution of 10 to is line-pairs/mm with luninous gains between 3000 and lo, 100 fos s:a

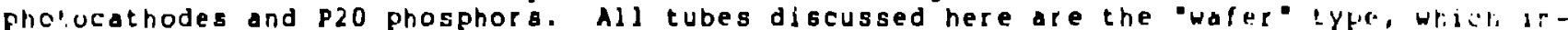
plies double proximity-focusing (proximity locused between photocathode anil Mill inpist ar wejl as between MCP output and phosphor). Several variations have been used or tortad ia-

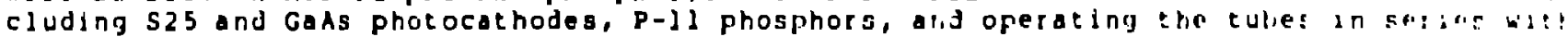
diode intensifjers to obtain higher gain. With the exception of the GaAs fhotocat?i.

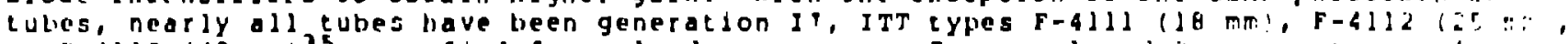

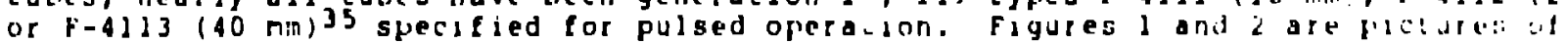

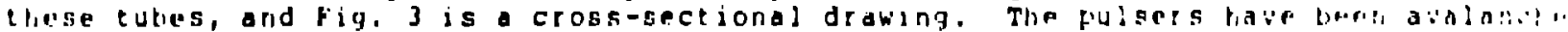

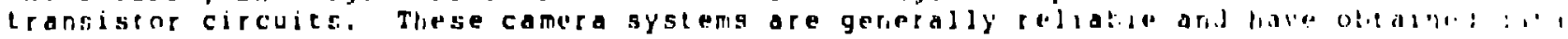
lut manj Los Alamus sludies.

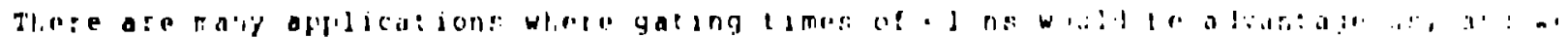

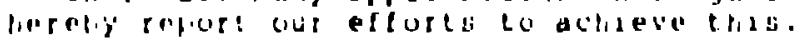

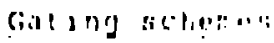

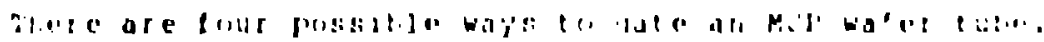

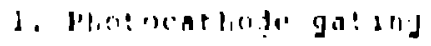

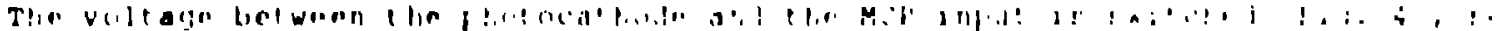

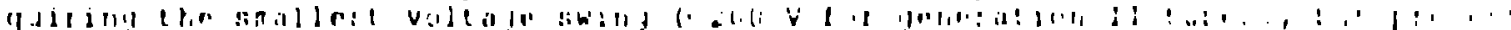

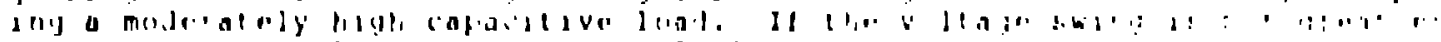

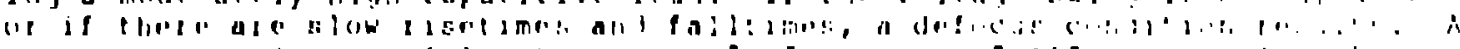

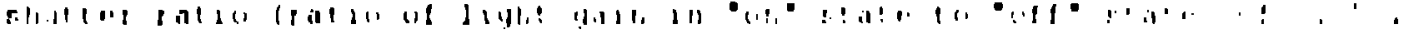

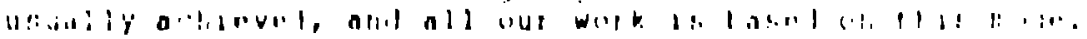

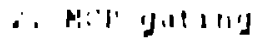

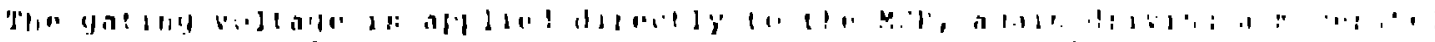

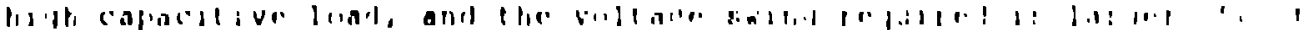

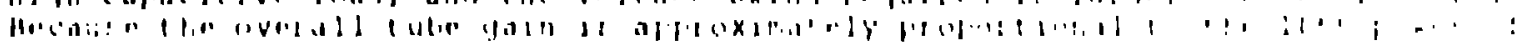

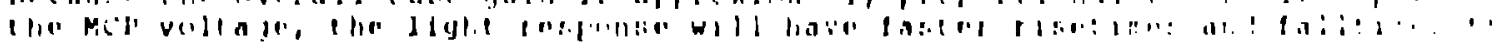

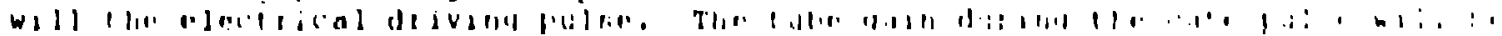

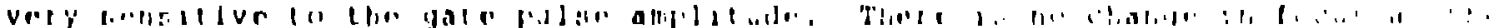

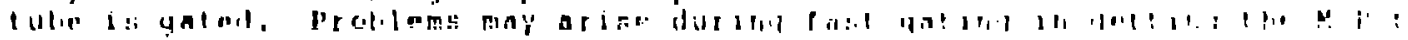

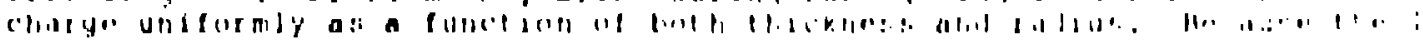

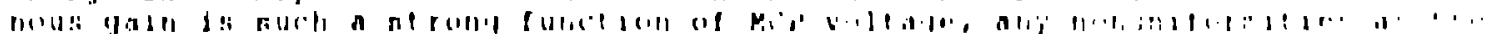

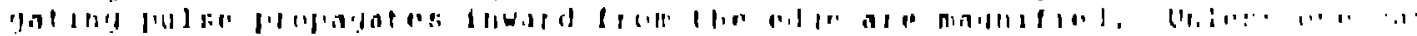

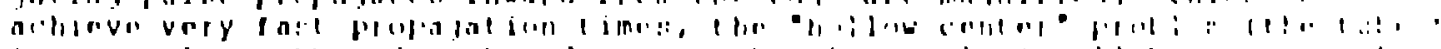

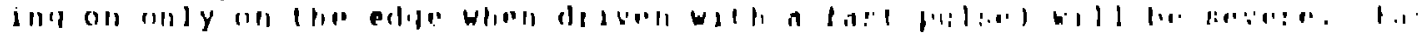

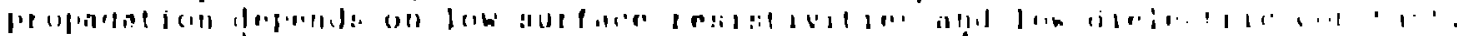

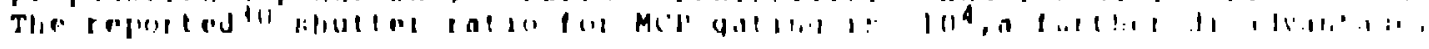

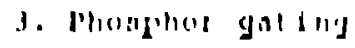

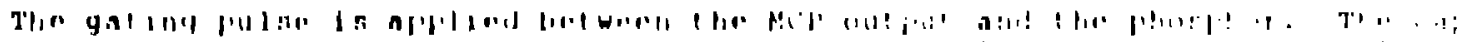

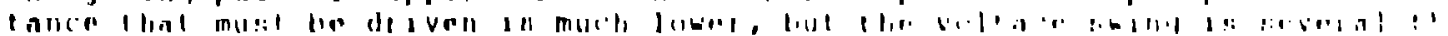

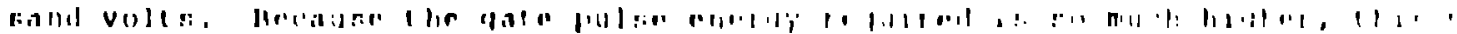

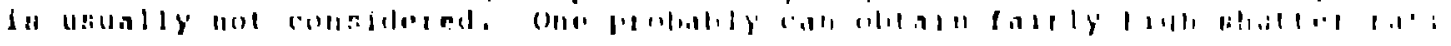


$3 !: 5$

4. Combined MCP-phosphor gating

An MCP wafer tube can a?. he gated by driving the MCP input and the phosphor with a single pulse. Ii, c icings and the dielectric constant of the MCP are such that a single pulse c he made to capacitively divide voltage appropria: $1: y$ between the MCP and the pho: Jr gap. Again, because the gate pulse energy required is high, this mode is, t usually considered.

The limits on gating speed of proximity; focused diode intensifiers were discussed in 197019 and 197121 by clement et al. and st. ed to be $\approx 100 \mathrm{ps}$. 5 similar limits, electtron transit time, gating signal shape, and photocathode and MCP input face electrode resistivity apply to MCP wafer tubes using photocathode gating. In the los Alamo caracas, the electron transit time for a full voltage gating pulse of $180 \mathrm{~V}$ is $=65 \mathrm{ps}$. This the dominant limiting effects are the gating signal shape and the electrode resistivity. Gating signal shape is defined by the gate pulse generator and its connection to the tuts electrodes. The electrode resistivity control: = both the propagation velocity and the spreading of the gating pulse as it propagates from the elise of the tube to the certes. Some work 19,21 has been done with tubes representing a section of a uniform parallel strip transmission line, an effective implementation that conceptually simplifies the analysis. However, to achieve the desired.j-ns gating with minimal re-engineering of th. tubes, we plan to drive them at up to four points ground the circumference, and in our analysis, we model the tube as a radial transmission line with a wavefront propajatiri ir.ward from the circumference to the center others have analyzed this configuration lis ir. a distributed resistive-capacitive model. $36-38$ This earlier work, while providing ar accurate andiysis of the R-C model, did rot allow simultaneous modeling of the idisar, it.. connections between the purser and the tube, the edge geometry of the tube, or tie $1, i_{1}$ rance of the tube.

The Syst r. Model

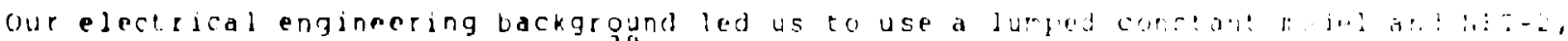

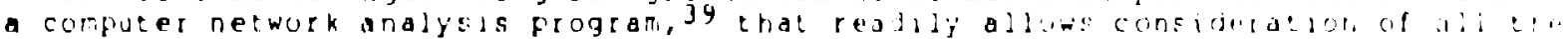
noted features and complete system evaluation of the electrical [eitirmince.

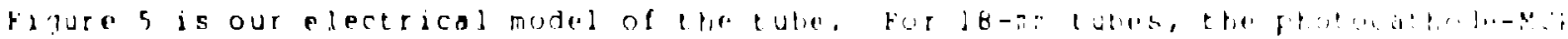

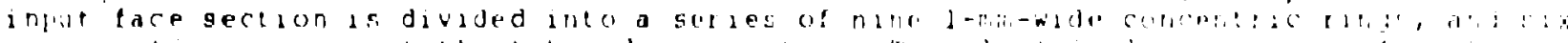

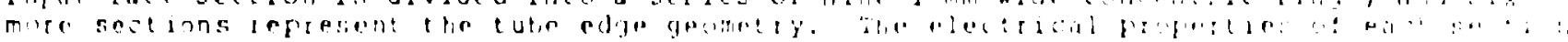

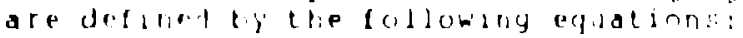

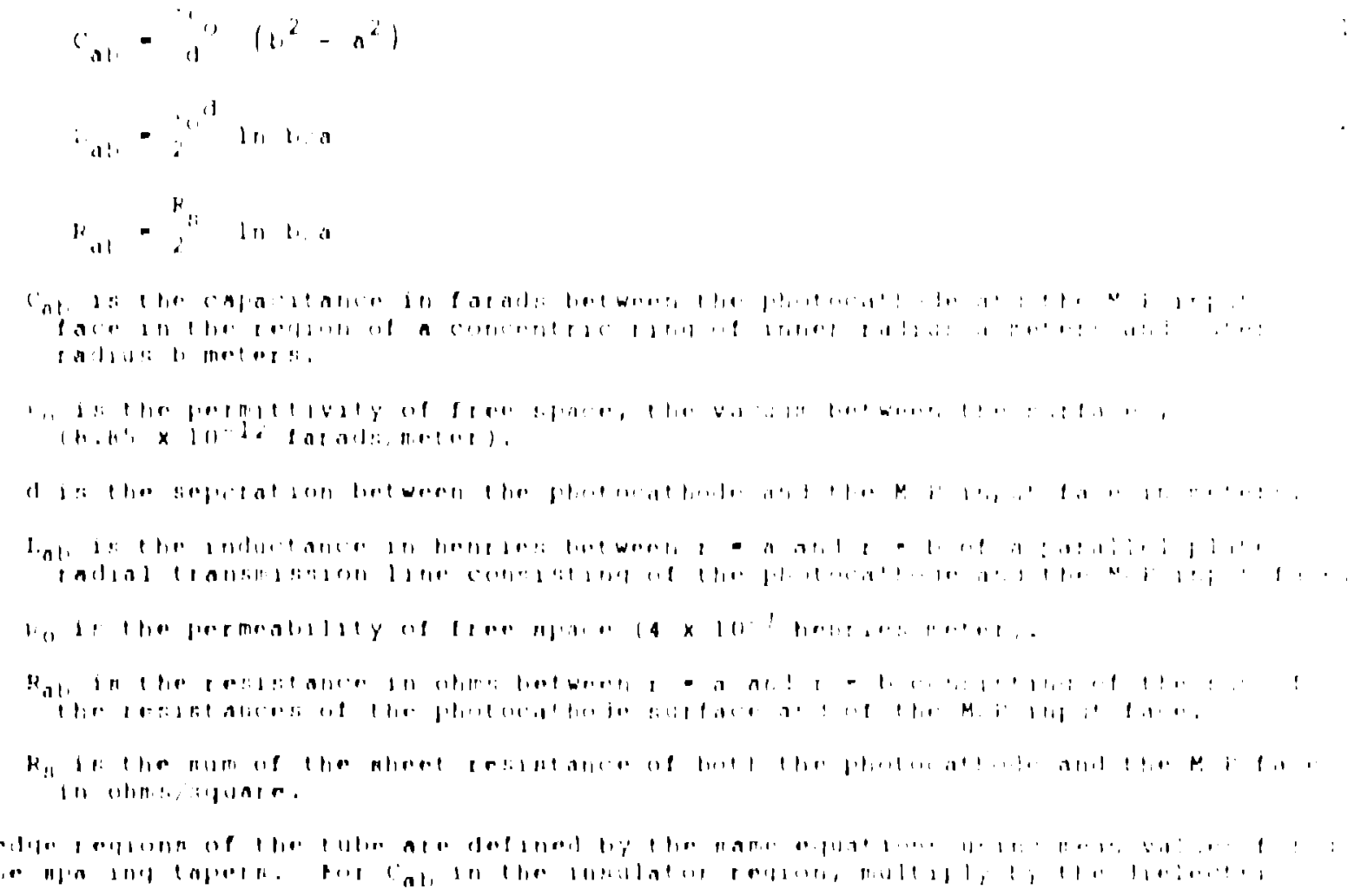




\section{$348^{-\leftarrow ?}$}

constant of the ceramic (8.9). On the ITT tubes, over half the tube capa.itance is cuf to the ceramic insulatnr region. Table 2 gives the values of each circuit element in fig. 5 fn: a $18-m m$ tube as a function of spacing and surface shet resistances. In the actual tube, the inductances and resistancas are distributed on both sides of the line, but for analysis they can be lumped on one side. This does not affect the validity of the model.

Table 2. Component Values for Tube Model (Fig. 5)

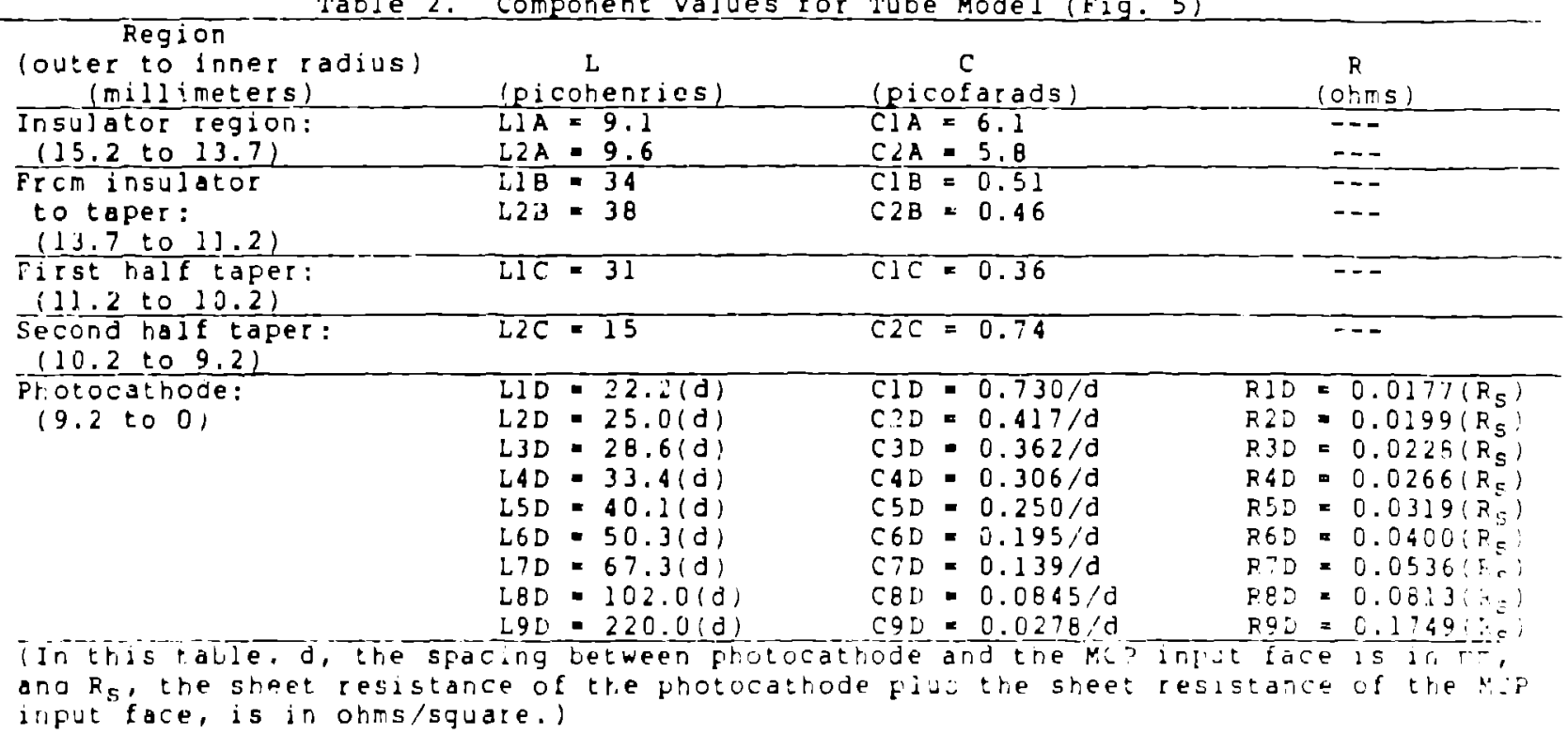

The mean lmpedance level of the tube between ariy tro radid for a low tesis:ive lose 15 given $b_{j}$

$$
\bar{z}_{a b}-V_{c}^{/ L}-\frac{d}{i} \int^{/ \frac{i}{2}} \frac{\ln (b / a)}{\left(u^{2}-a^{2}\right)}
$$

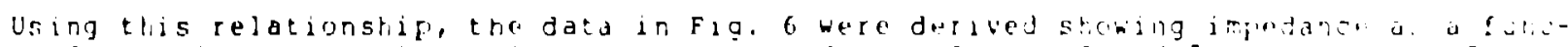

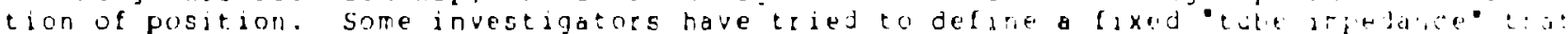

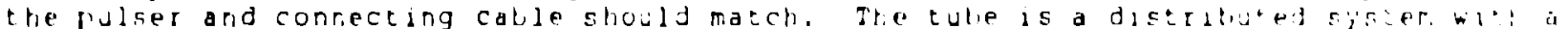

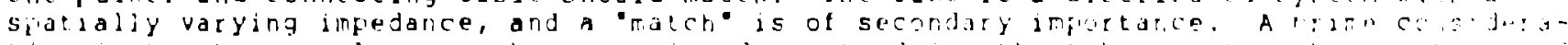

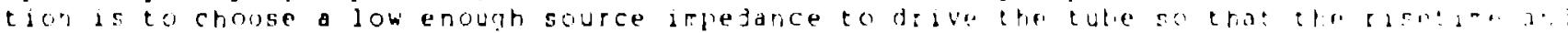

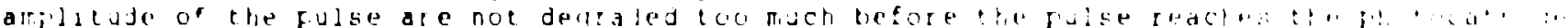
area.

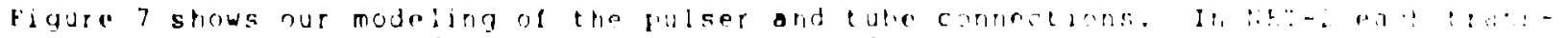

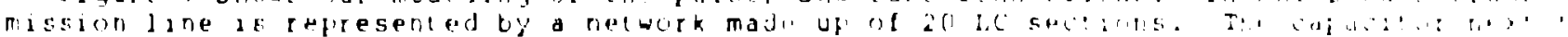

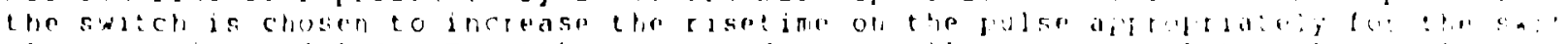

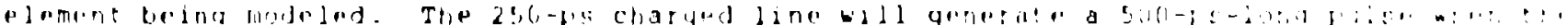

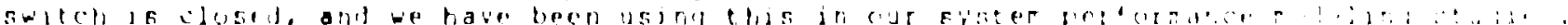

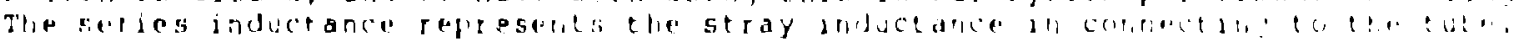

$$
\text { Pinleding re: is: }
$$

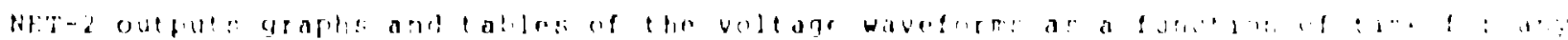

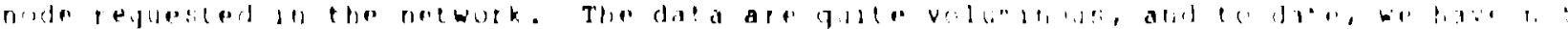

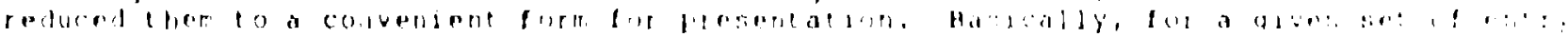

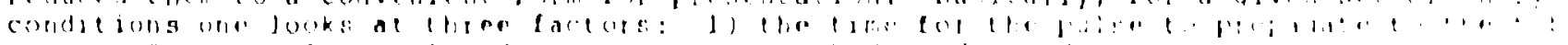

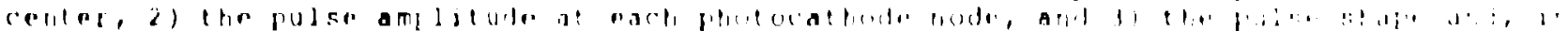

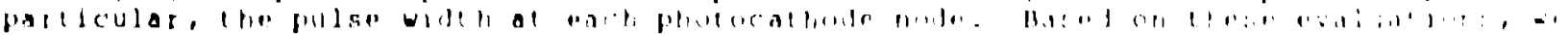

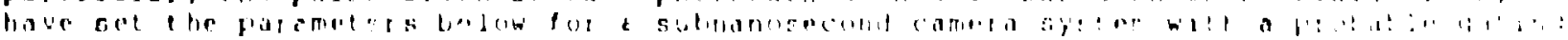
timp limitatien of joll je.

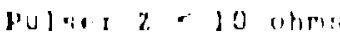

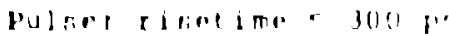

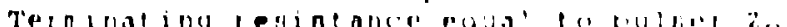

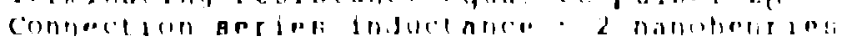

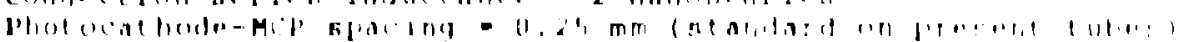

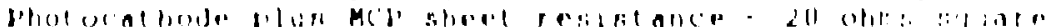




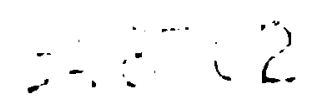

Achieving these parameters requires modifying both tubes and gate pulse generator techniques as described below.

\section{Tube modifications}

We are procuring tubes with four modifications.

\section{Photocathode sheet resistance}

520 and 525 multialkald photocathodes have inherently high sheet resistivity. kifen tubes are ruilt for gating applications by ITT, the photocathode is deposited on a prugietary multimetaliic substrate. This permits most $18-m m$ tubes to be gated for 2 . 5 ns. For faster applications, GaAs photorathode tubes, which have very jow sheet resictance (possibly cl ohm/square) as well as higher guantum efficiency, might be used. Urfortunately, Gas is even more prone to poisoning than multialkali cathodes, and for protection, generation II tubes use an $\mathrm{Al}_{2} \mathrm{O}_{3} \mathrm{film}$ at the MCP input tc protect the caihcde frcin positive ion feedback or other sontamination. This tilm requires significantejectron energy for penetration, and thus the gating voltage requirement is $\sim 900 \mathrm{v}$. Becalse of this, coupled with the scarcity of generation II tubes, we have given little serious attention to using GaAs, although we did some experiments we a standard military night vision tube during 1981. We were unable to produce the holdow center effect with this tube. To lower the sheet resistance of multialkali cathodes, various schemes have tef? used including implanted metal meshes, metal film underlays, and transparent metal oilio semiconductor underlays. Generally, the cathode is incompatible with many of the desirel underlays. Thomasto reported a very promising system where a metajoxide semiconductor underlay is overcoated with a thin (2.2 - il) layer of silica to provide chertical isciatlon between the photocathode and the conductive substrate. In the fast gating moje, lhe : ir. is coupled to the photocathode capacitively through the silica. At the ireguericies livolved, the capacitive reactance is low enough tn be considered a direct connectior. low frequencies, a dc path is provided by direct connections to the edge of lie fha:sat ode. The knowledge of transparent semiconductor conductive coatings tias iricrearel a.: -

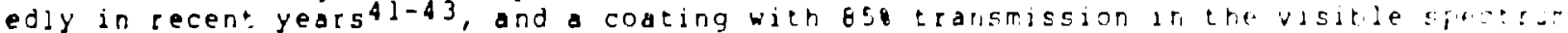
and a sheet resistance of 10 ohmsisquare can be made.

\section{MCP input face sheet resistance}

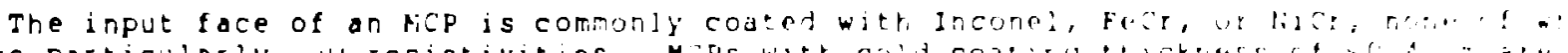

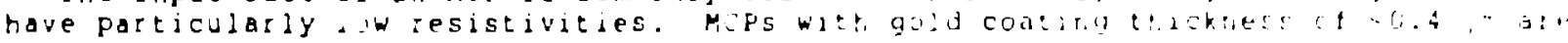
avaliable and have sufficientjy low surface reslstivity.

\section{Infut connection inductance}

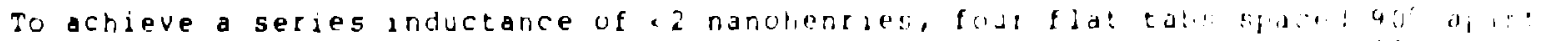

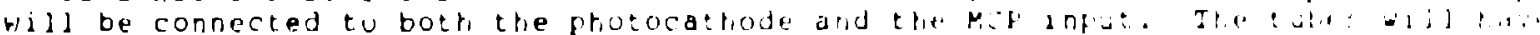

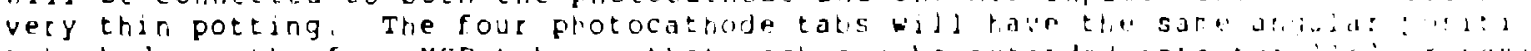

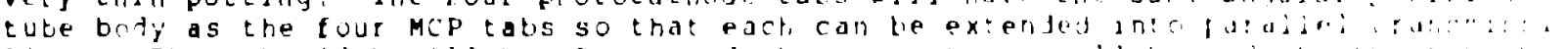

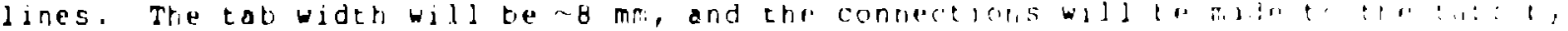

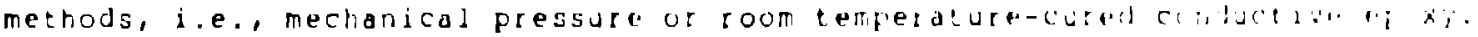

The inductance of the internal connections to the f :

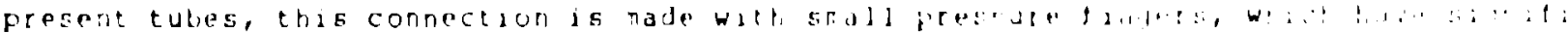
inductance.

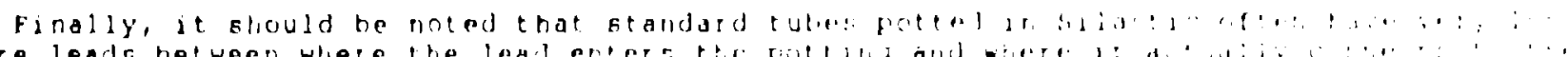

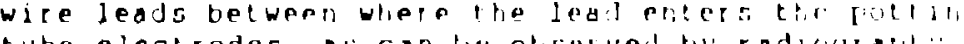
tube electrodes, as can lie. obsietved by radicialili.

\section{Euge cafacitani...}

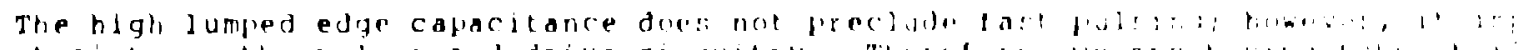

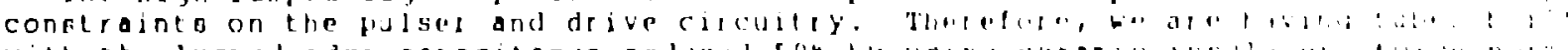

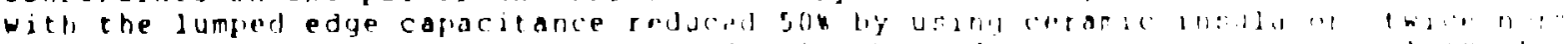

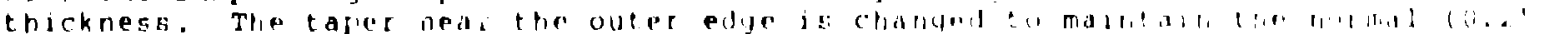
photocathode-mcer face Bpacing.

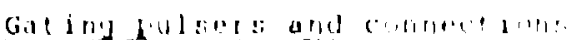

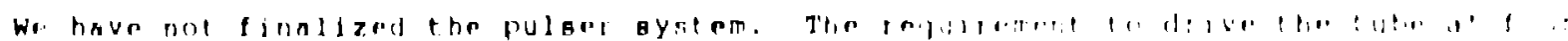

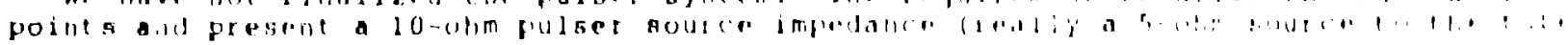


because the line is siunted by a 10-ohm terminating resistor) requires driving four a loads simultaneously. With the exception of photoconductive switches, all switcting tect. niques have too much jitter to rely on four separate pulsers. Sflitting a single pulser to several loads can be done capacitively, with transformers, resistively, with tapered transmission lines, or with microwave combiners. We are evaluating the last three riethods. Note that resistive dividers have high power losses. A $1000-v$ pulse on a $50-0$.r. line resistively divides into four $200-V$ pulses into 40 olms, an 80 power loss.

A further complication is that on a real camera one usually wants to operate the ptosphor at ground potential to avoid current leakage through the fiber optic coufling fia:e, and this puts the photocathode at high voltage. Thus one either floats the pulser at tig voltage or uses coupling capacitors to provide isolation. If c upling capacitors are required, they must be carefully selected to provide low series irductance; therefore, ceramic capacitors designed for use at microwave frequencies should be usea. Alsc, adequate dielectric stiength must be provided because breatjobn of a couplirg capacitor hoj:d destroy the tube. Similarly, load resistors at the tube mist have ver $j$ ion ariactarce, and inicrowave freguency resistors should be used.

\section{spark gas pulsers}

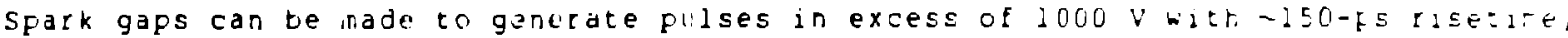
but it is very difficult to simultaneously produce vely jow trigge: jacter. Fct a fae: canera to be useful, the trigger jitcer should be a small traction of the exfiseds tirt. Laser-triggered spark gaps tend to have significantly lower jitter tran ejectricasij i gered gaps. Most sptzk gaps reguire freguent adjustrents of gap; ejectrojes; ari ijz

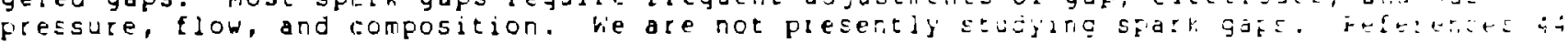
and 45 discuss nigti-performance spark gaps.

Avajarcte trans'stors

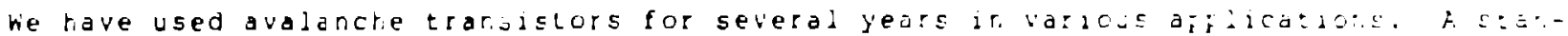

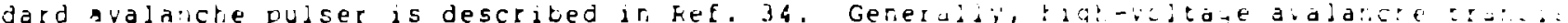

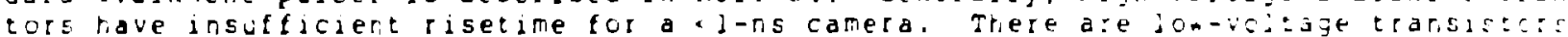

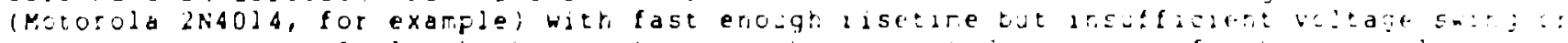

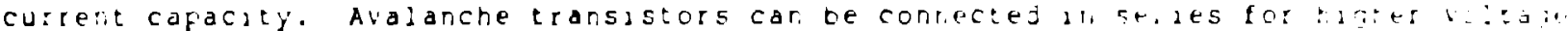

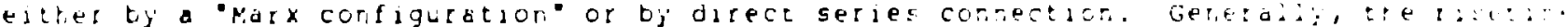

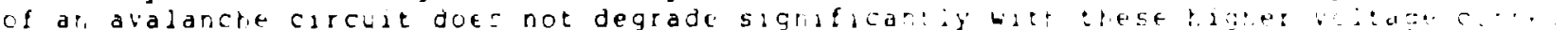

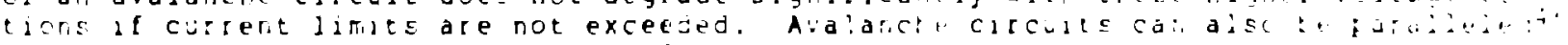

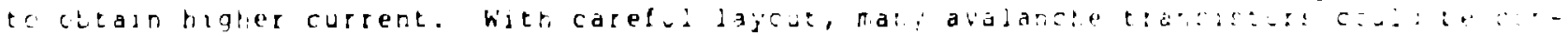

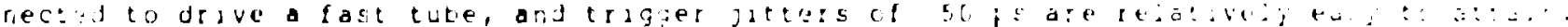

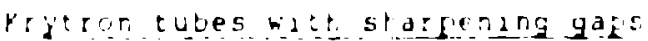

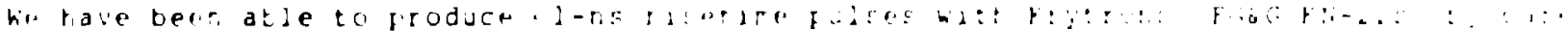

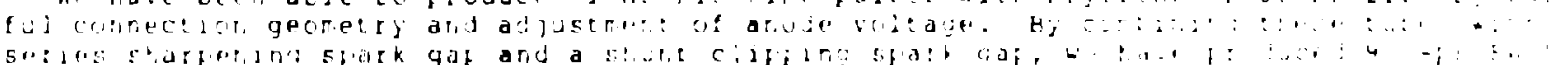

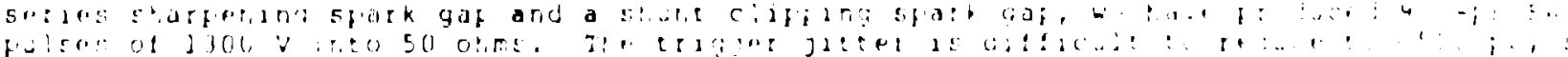

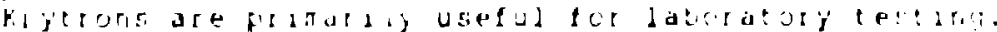

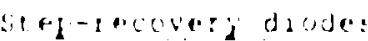

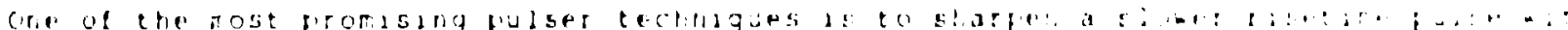

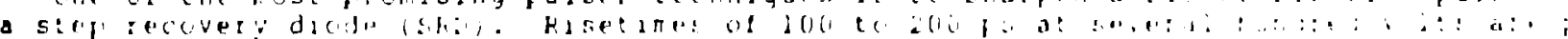

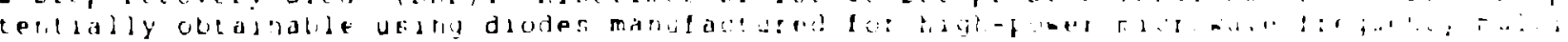

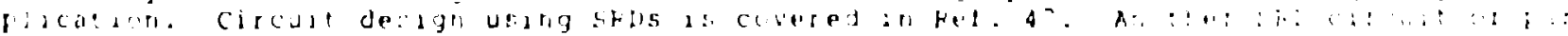

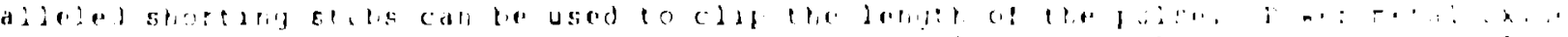

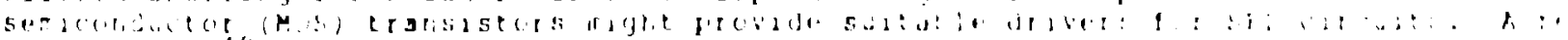

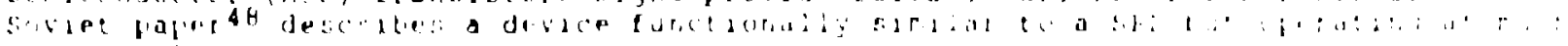
blgler voil alde.

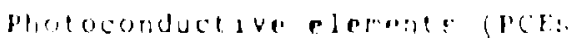

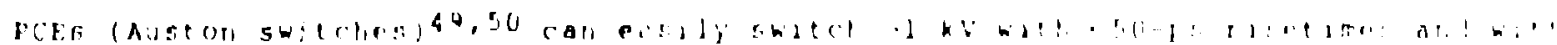

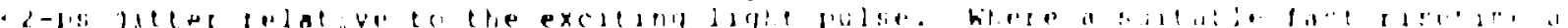

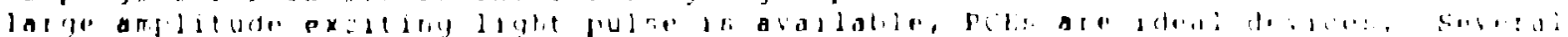

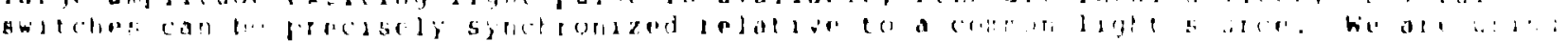

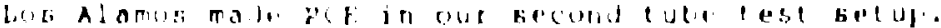

Tulie evalua! joli

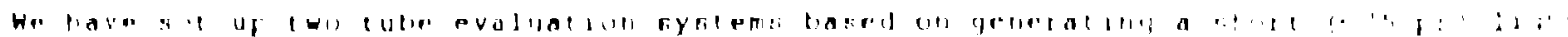

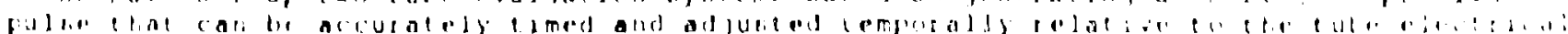


gating pulse. In essence, one gates the tube and then illuminates the photocatrode with the fast light pulse at some known time relative to the gating pulse. This allows us i. observe the temporal lijht response of tue gating process at various points actoss the photocathode surface.

Our first system (Fig. O), which is fully operational, is based on a $1000-v$, l-ris lisetime mercury relay pulser and a solid-state laser diode lizht source. The mercury relä pulser generates a tast rising $1000-V$ pulse, the major portion of which is sent thiost. a low-loss delay line consisting of a 5-ns adjustable air line and a $75-n s$ cryogenic iire operating in liquid nitrogen. The pulse length is then clipped to 600 pjaridapijej

the tube. A sample of the mercury relay pulse is used to trigger a hamanatsu lacer jajje pulser, which has an internal trigger delay of $275 \mathrm{~ns}$ and an incernal trigger Jit:er of $=30 \mathrm{ps}$. The laser diode output is a 75-ps-wide, 850-pJ pulse at 820 rim (near irferares.) The guantum efficiency of an $\$ 20$ photocathode at this wavejength is near 0.018 , bu: je still has adequate sensitivity to allow testing the tube for temporal response. ate si: con intensified target (SIT) TV system provides a convenient method of Vieisrat

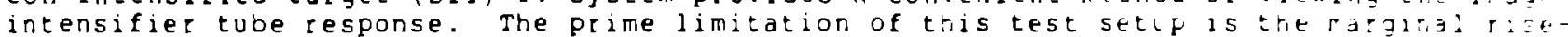
time of the fulse from the spire mercury relay pulser.

Our second test setup (Fig. 9) under develupmert uses a nitrogen laser to tat fur a dye laser emitting in the visible and to drive a photoconductive swltch. 2 re dye i ar

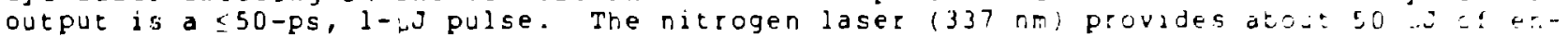
ergy spijt equally between the photoconductive switch and the dye daser. Acculat: is provided by varying the light path length. This systert bill provide taster rist: - i.

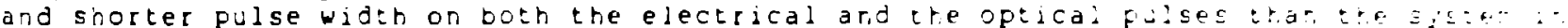
Fig. 9 .

\section{Conclusions}

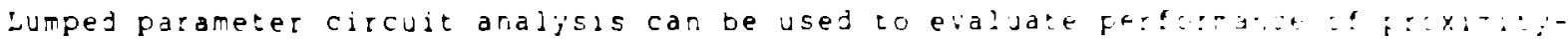

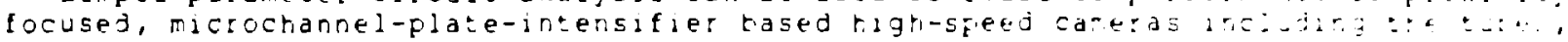

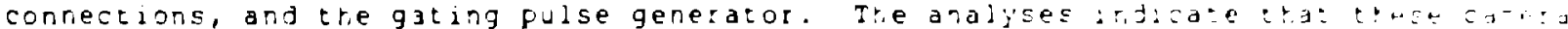

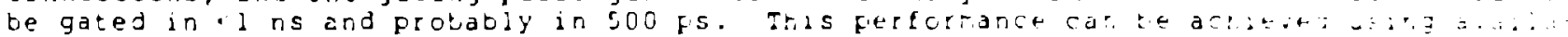

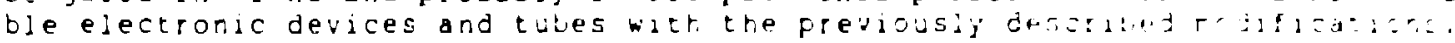

\section{Azkrowedger.'s}

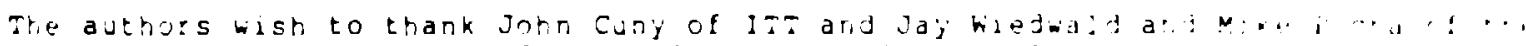

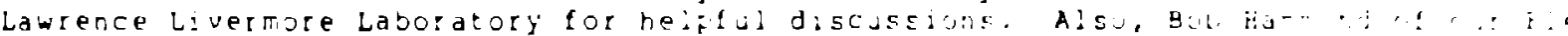

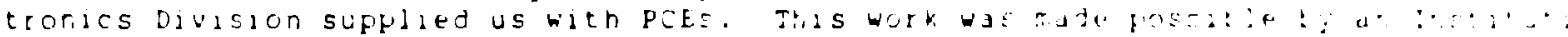

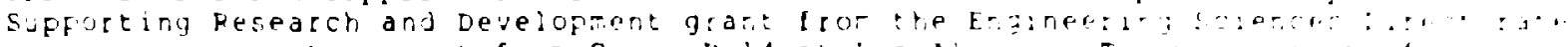
riajor frocurement support fror Growp p-14 at ios ausices of the lis Department of Eriergy'.

\section{kef rereres:}

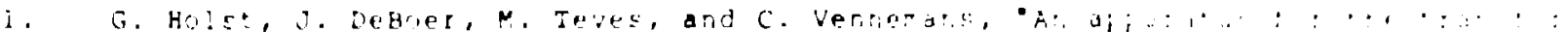

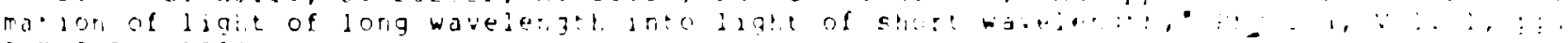
$2 y ;-3 ! 5 . \quad 19 j 4$

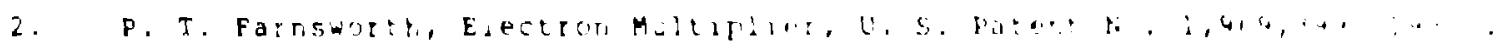

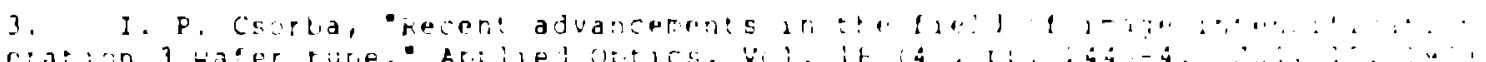

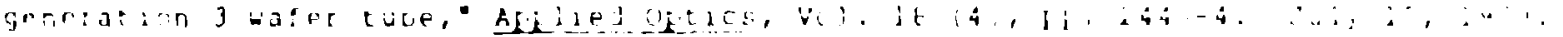

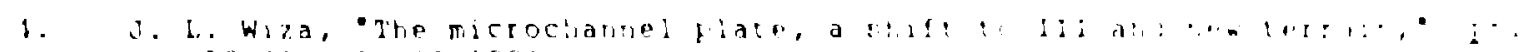

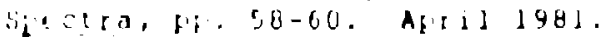

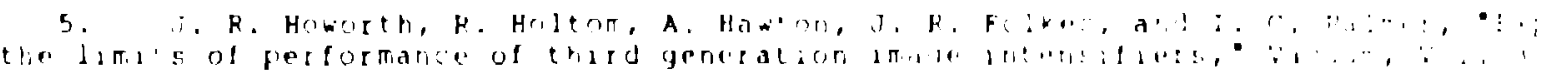
(11/12). pl. 351-5. 1986.

6. J. L., Wiza, Micro $162, \mathrm{PP} .3 \mathrm{H}^{7}-6(1), 979$.

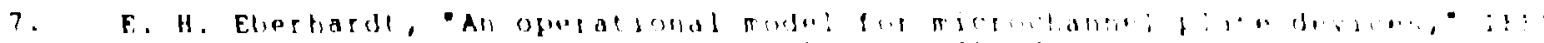

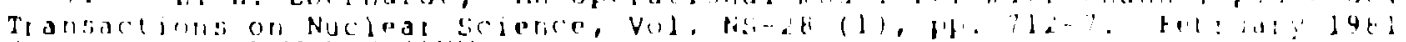

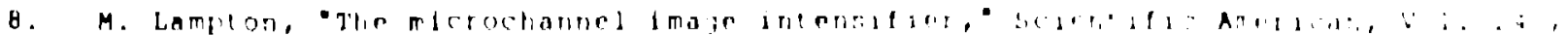
Ir. $62-71$. Novemier 1961. 
9. P. Schagen, "Image tutes with clannel electron muitiplication," Advarices i- iraze Pickup And Display, vol. 1, pp. 1-69, Academic Press 1974.

10. Technical Manual ReS-0735: Characteristics And Applications of Microchariti Plates, put:ished by Hamamatsu T.V. Co. utd, 1126 lnchino-cho, Hamatiatsu, Japan. igei.

11. Publication MCP-28190: "Applications for Microchannel Plates," putlished ty varian, Light Sensing and Emitting Division, 6ll Hansen Way, Palo Alto, CA 94303.59.

12 Technical Information 31, (TP 1561): "ricrochannel plates, putished bj Ma:ja: Limited, Mullard House, Torrington Place, Londor, England, WilE $7 \mathrm{HE.} 1976$

13. G. Eschard and R. Polaert, Tube obturateur pour photographic ultra-rapije", Proceejings of the Bih International Congress on High-speed protorafti. Stockholr., Swejen, June 1968, PP. 57-60, wiley 1968 .

14. H. Bacchi and J. Marillead, "Dispositifs de prise de vues ilera-rafijes a ieri de pose compris entre 5 et $500 \mathrm{~ns}$, ibld, pp. 61-3.

15. E. Laviron and H. Bdccti, "Camera a image integrale de l ns je djee douverture,' íld, FP. 61-3.

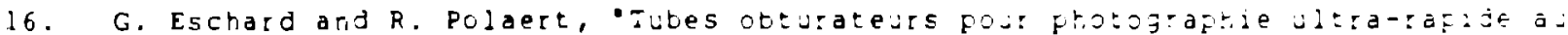

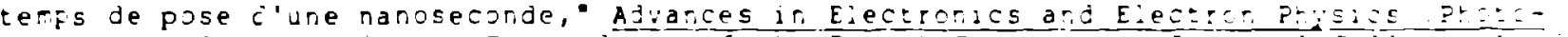

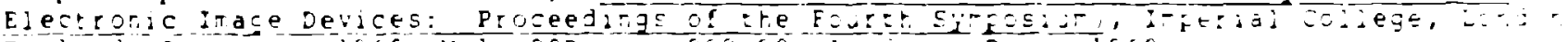

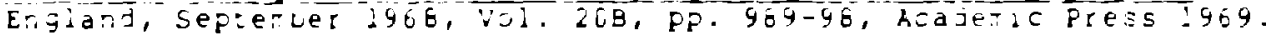

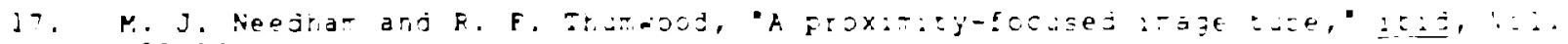
ZEt, Fir. $229-36$

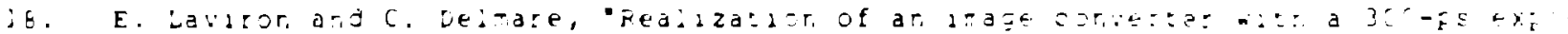

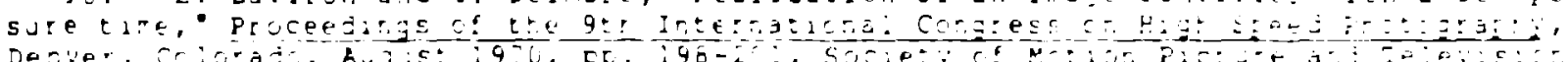
Engineers. d9-ú.

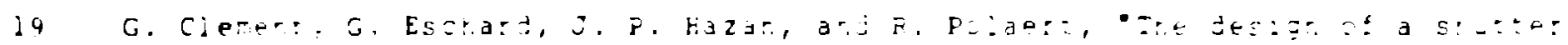

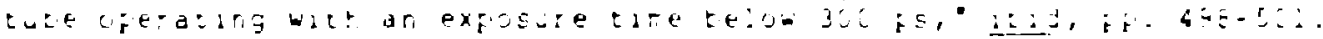

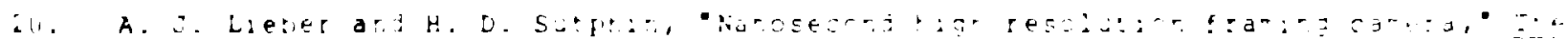
Pe

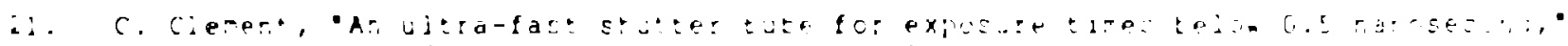
L a d P il:

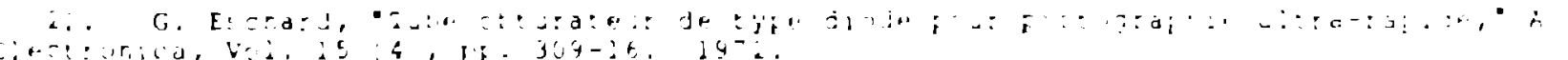

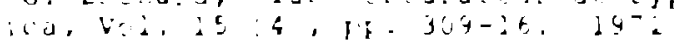

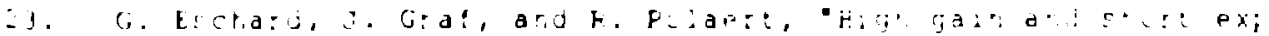

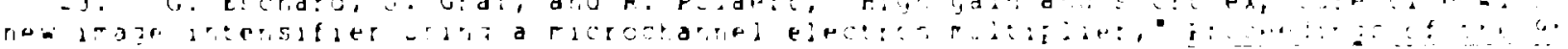

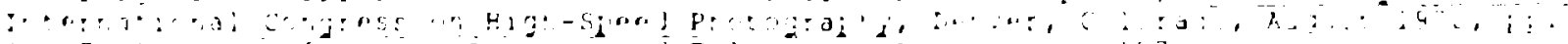

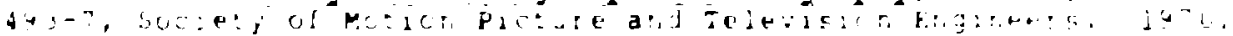

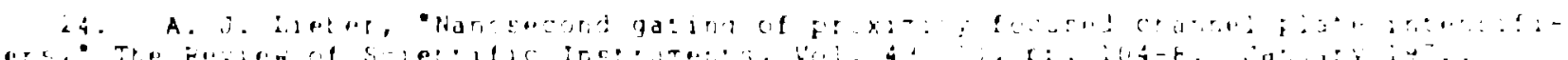

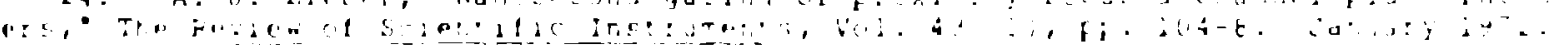

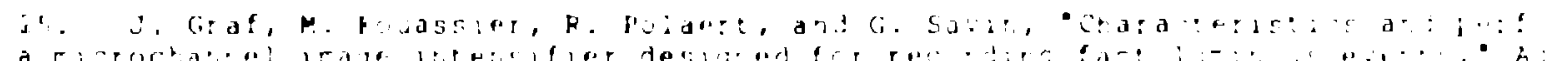

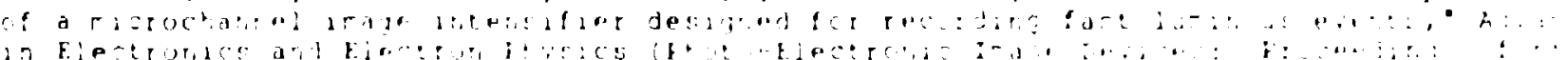

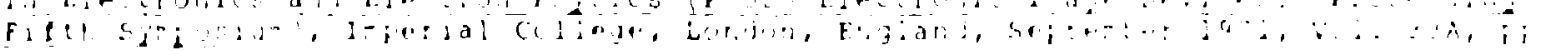
$145-5, ; 9 ;$

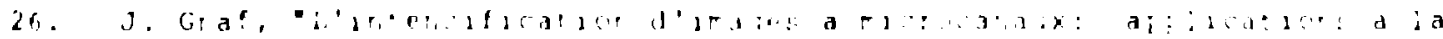

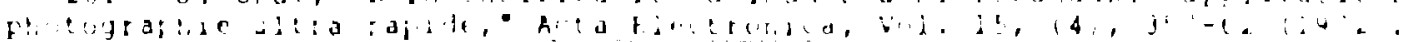

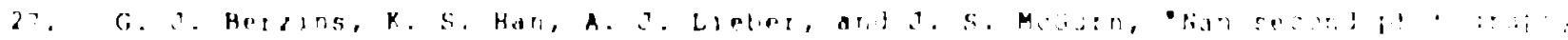

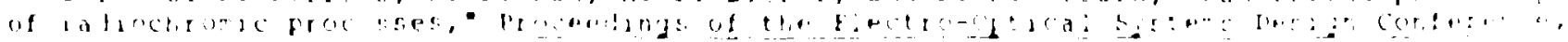

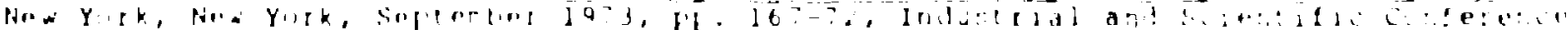

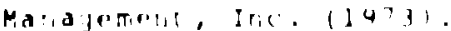


28. G. Eschard, The microchannel plates: a survey of the possibilities of channel multipliers arrays in nano and picosecond detection ard imaging, PIoceedings of the lith International Congress on Higll Speed Photography, London, England, Septeriber 197t, pp. $163-9$, Chapman and Hall Led. 1975 .

29. R. Polaert and J. Rodiere, Improvement of the performances of high speed cinematography through the use of a proximity focusing aicrochannel image intensifier, itid, pp. $170-7$.

30. D. J. Bowley, A. E. Huston, and M. G. Wilson, 'single-shot photography with channel-plate intensifier tubes," The Journal of Photographic Science, Vol. 23, Pp. 165-E. 1975 .

31. A. E. Huston and K. Helbrough, "Photography with gated microchannel plate intersifiers,- Advances in Electionics and Electron Physics (Photo-Electronjc image Devices: proceedings of the seventh symposium), Imperial Coilege, London, England, September ig7z, vol. 52, PP. 253-63. 1919.

32. O. G. Winslow, W. C. Davis, and W. C. Chiles, "Multiple-exposure imageintensifier camera," Froceejings Sixth Sumposium (International) on Detonation, ACR-2zl, Coronado, California, August 1976, pp. 664-7, Office of Naval Research-Department of tre Navy (U5).

33. G. J. Yates and N. S. P. King, Image stutters: gated proximity focused microchannel-plate wafer tubes vs gated silicon intensified target vidicons, (this congress, 1982 ).

34. A. Lundy, J. R. Parker, J. S. Lunsford, and A. D. Martin, Avalanctie transistor Puser for fast-gated operation ot microchannel plate image intersifiezs," IEEE Tráż三tiors on Nuclear Science, Vol. NS-25 (1), pp. 59:-7. February 1978.

34. Manufactured by ITT, Electro-Optical Products Division, Tube and sersor Laioratories, 3700 East Pontiac Street, Eort waye, IN 46803.

36. Yu. V. Bondarenko, V. I. Budarnykh, A. M. Iskol'dskil, V. F Krasnov, and I. P.

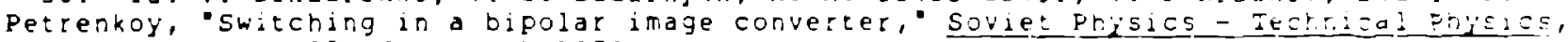
vol. 24 (3), PP. 354-6. March lo79.

37. J. L. Detch, Jr. and J. H. Ogle, "A distributed R-C radia: transisission lirettary applied to the gain characteristics of gated microchariel-plate iraje irtersifiers, Ejs: Energy Measurements Group, Santa Bartara Operations, ReEort No. 1163-2404. Jure I9É.

38. J. L. Detch, Jr. and B. W, Noel, "Radial plize propajation and iriedarce crazaczeristics of optically shuttered channel intensiller tubes, Procerd:ngs ot the ios Asar

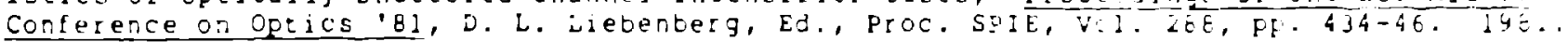

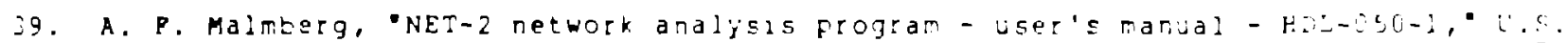
Army Material Command, Harty uiamonc Laboratories, wastiriz:on, DC 20438 . Se; terier ig j.

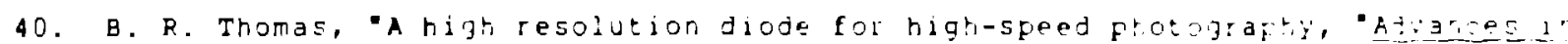
Electronics and Electron Physics, (Photo-Ejectroric Inize Devices: proces a

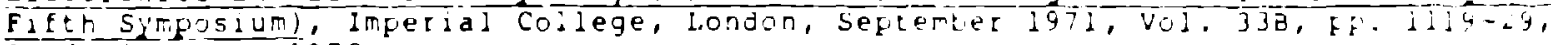
Acajenic Press 1972 .

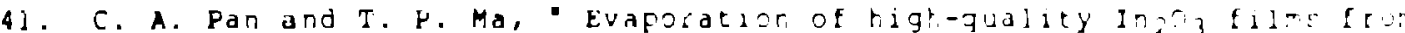

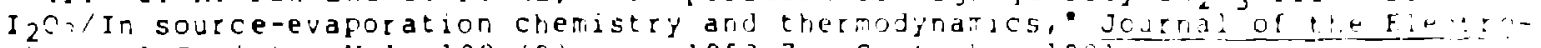
che cal Society, vol. 128 (9), pp. 1953-7. Sepiembor 1981 .

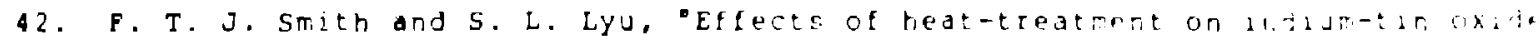
films, ibid, vol. 11, pp. $2388-94$. Noventer 1961.

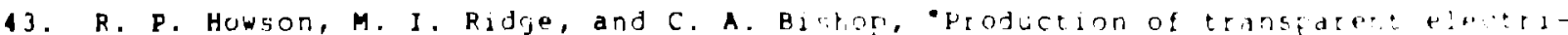

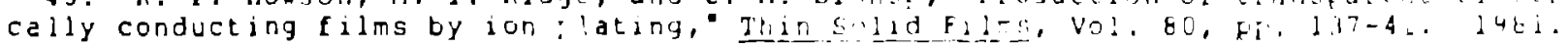

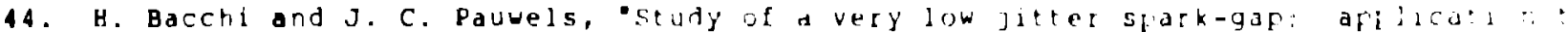

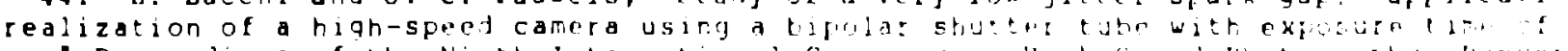

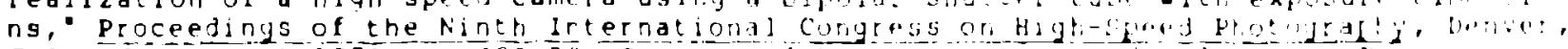

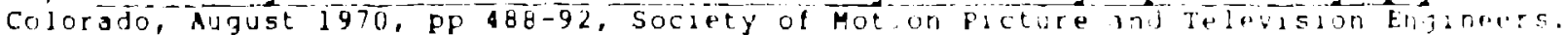
1970 . 
45. M. Blanchet, "High-Tension Pulse Generators ard Attenuators in the Nanosecond and Subnanosecond Range, ibid, pP. $112-9$.

46. P. R. Prince, Paralleling avalanche transistors, proceedings of the IEEE, Vol. Ez (3), pp. 304. March 1965 .

47. HP Application Note 910: Pulse and Waveform Generation with Step Recovery Diodes,' Hewlett-Packard Company, 1820 Embarcadero Road, Palo Alto, CA 94303.

48. I. V. Grekov, A. F. Kardo-sysoev, and S. V. Shenderei, "High-power subnanosecctid semiconductor pulse peakers, Pribory i Tekhnika Eksperimenta, Vol. 4, PP. $135-6.401 y-$ August 1981 .

49. R. B. Hammond, N. G. Paulter, A. E. Iverson, and R. C. 5mith, Proceedings of the International Electron Devices Meeting, pp. 157-60, Washington, DC, Decerter l9gl Institute of Electrical and Electronic Engineers. 1981.

50. G. Mourou and W. Knox, "High-power switching with picosecond precision," Applied Physics letters, Vol. 35 (7), PP. 492-5. October 1979 .

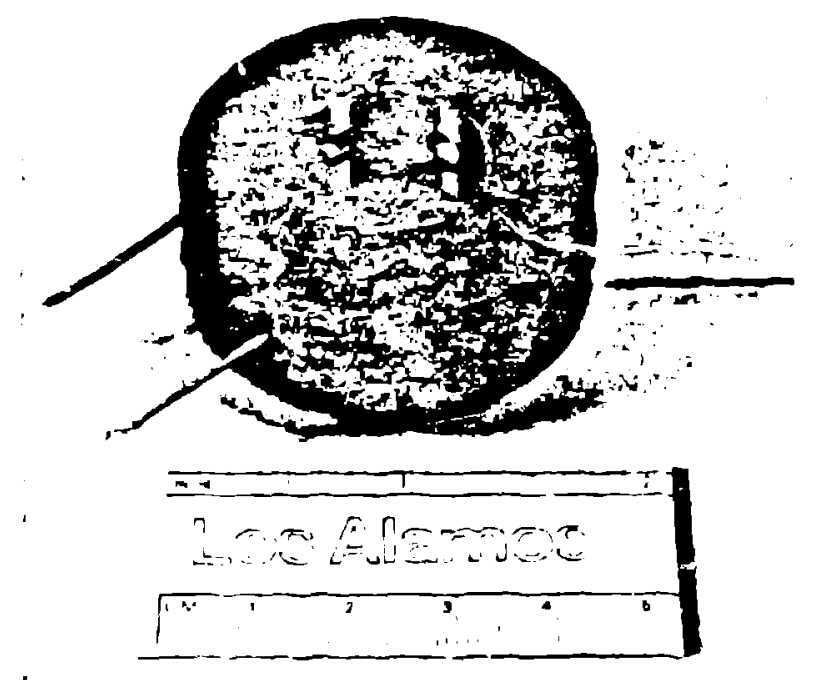

Figure l. Pottej $18-m i a$ MCP imaje intensjfier tube.

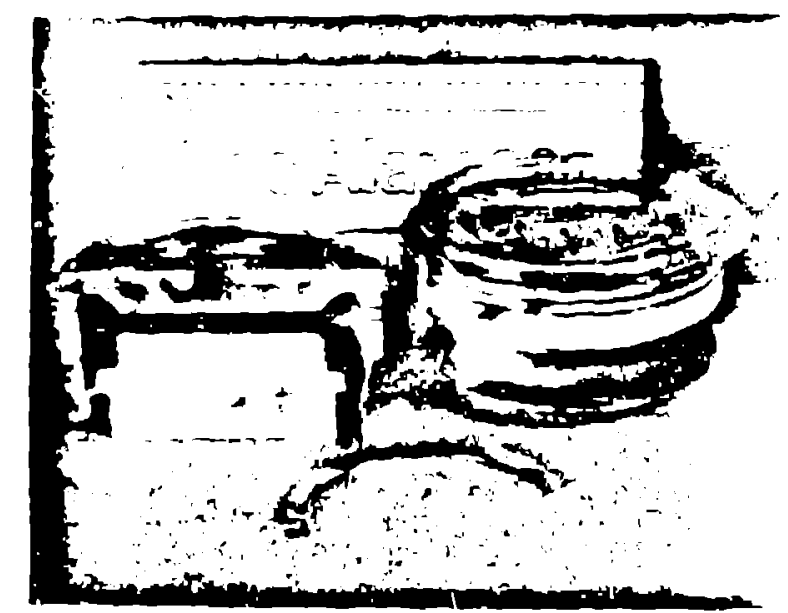

Figure 2. Unpotted $18-m r$ map image intensiljer tubes. One of the tubes 1 . we in half to show internai const: tut i 


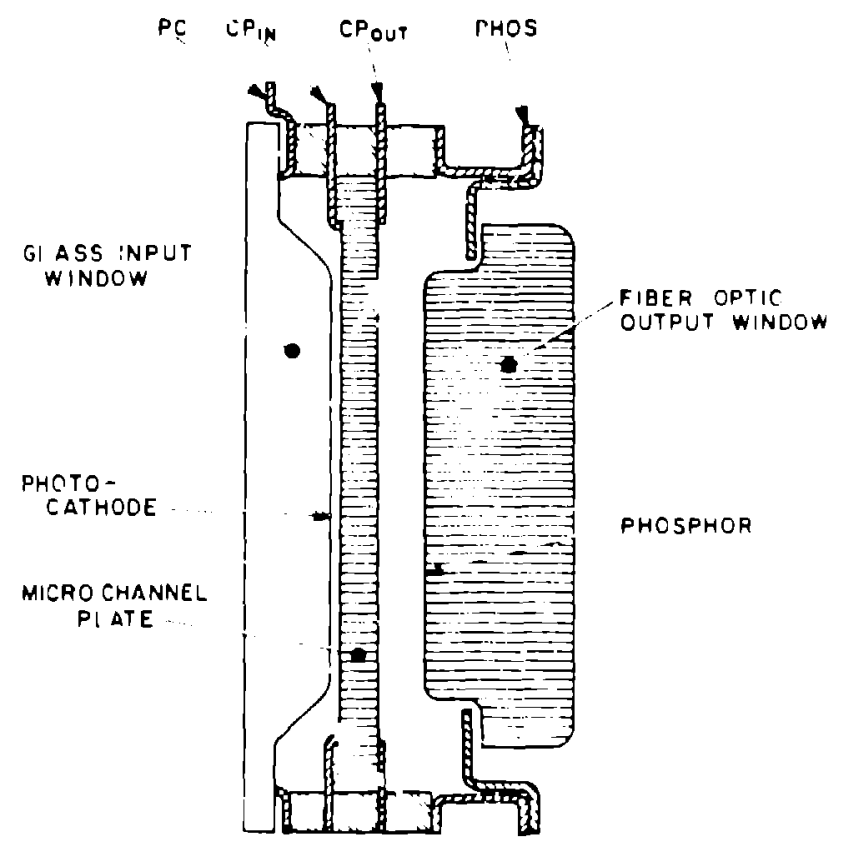

Figire 3. Cross-sectional drawing uf a typical microchannel plate lmuge inisn: -

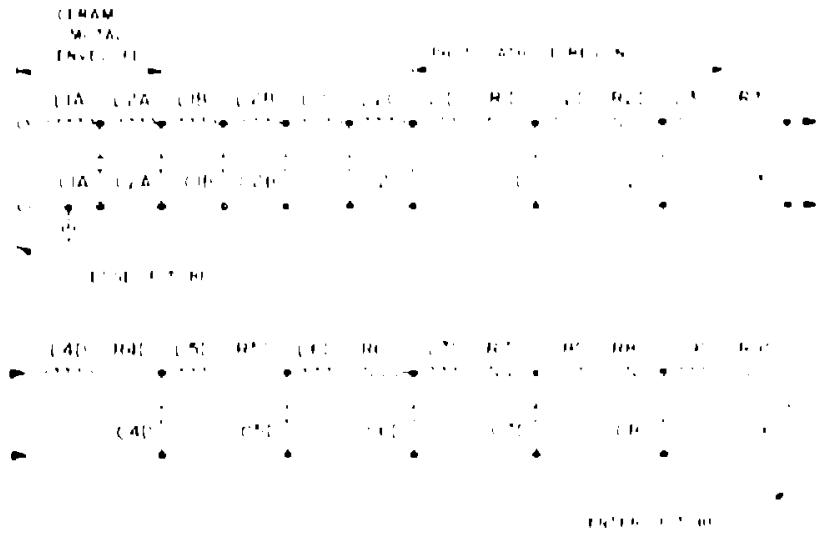

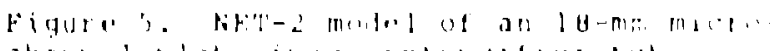

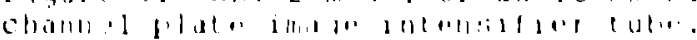
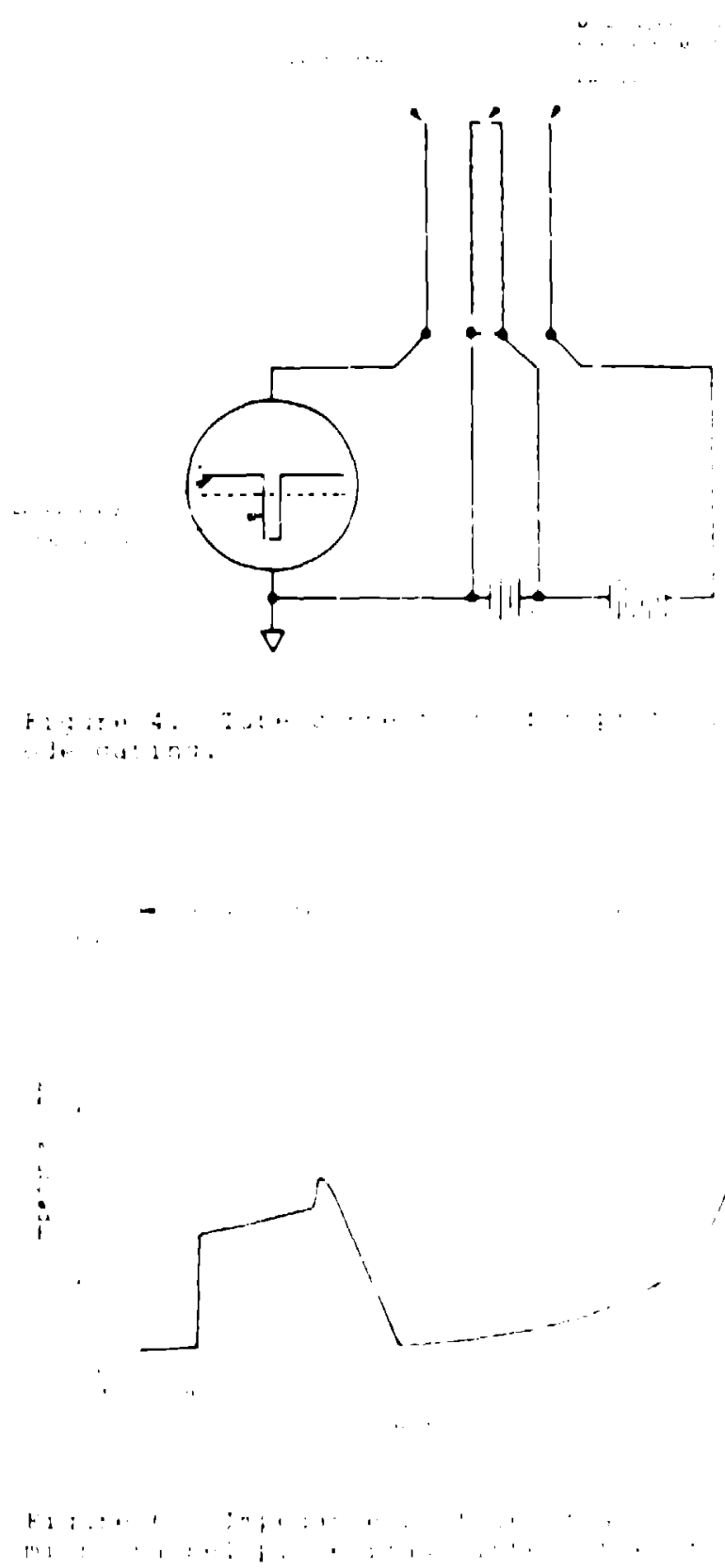


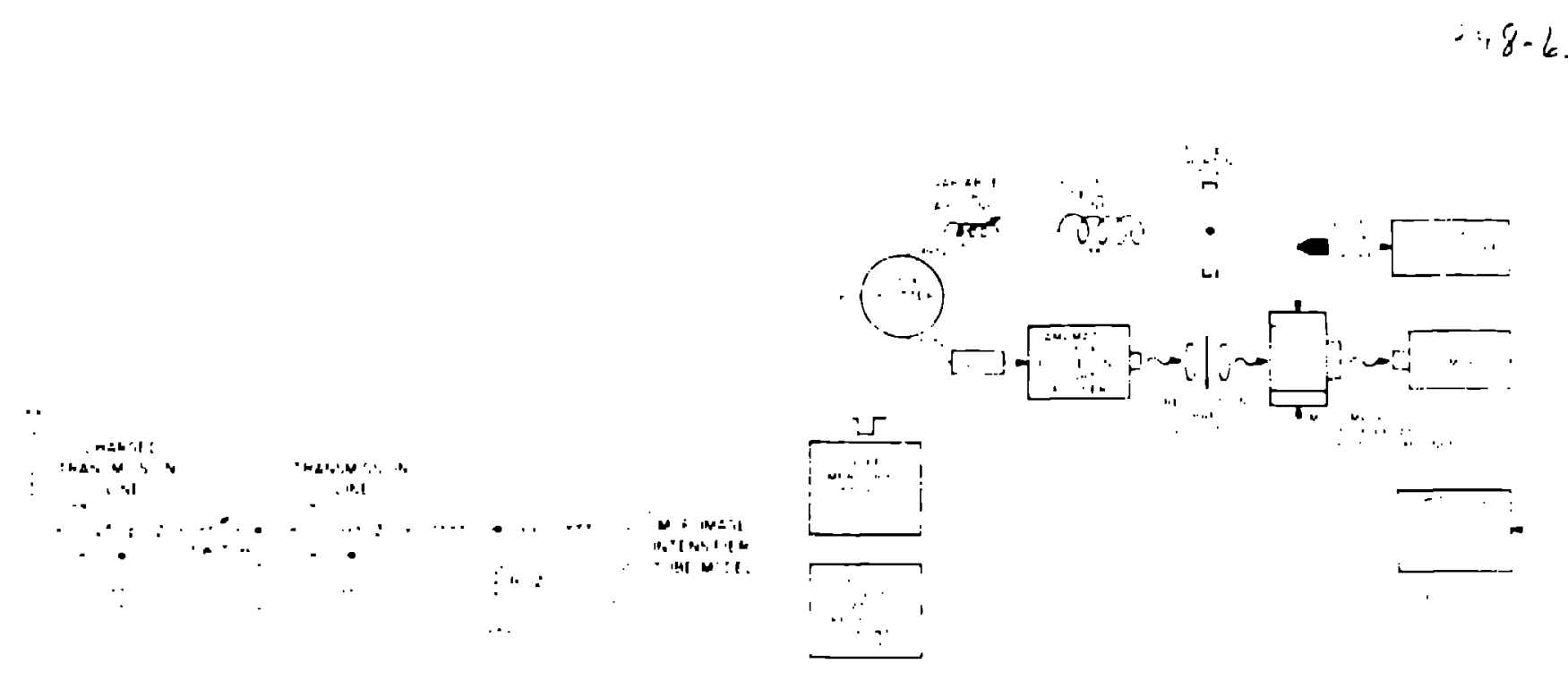

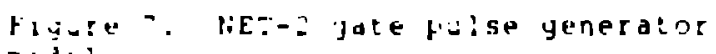

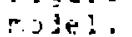

Figure 8 . Mercury relay-iaser jioje sj'sten. for tube gatang characterization.

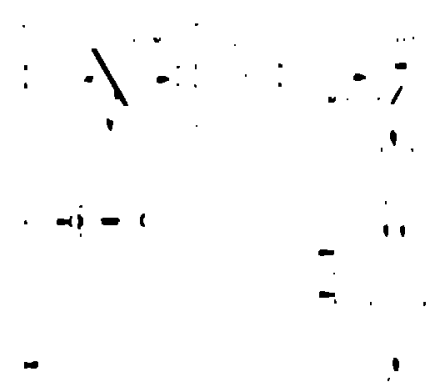

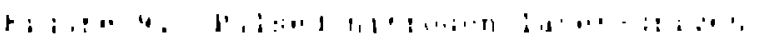

i. 